\title{
A escrita como jogo \\ Desafios e contraintes na literatura do Oulipo
}

\author{
Vinícius Carvalho Pereira (IFMT)
}

\section{Resumo}

Na França da década de 60, o grupo Ouvroir de Littérature Potentielle (Oulipo), sob presidência de Raymond Queneau, propôs uma nova forma de ver a Literatura, profundamente influenciada pela Matemática. Para os autores desse grupo, o texto literário, como um jogo, deveria ser produzido na condição de um desafio, materializado sob uma restrição formal, por eles chamada de contrainte. Tais restrições, em alguma medida semelhantes às tradicionais formas fixas da literatura ocidental, potencializariam, porém, essas regras clássicas em restrições muito mais radicais, a fim de tornar o ato da escrita uma verdadeira partida de tabuleiro, em que as palavras, como peças, teriam regras de movimentação, associação e posicionamento muito claras. O presente artigo tem por fim analisar essa aproximação entre Literatura e desafio formal nos jogos oulipianos, apresentando, para tanto, as principais contraintes concebidas pelo grupo e alguns dos textos resultantes dessas lúdicas restrições.

Palavras-chave: Oulipo; jogos verbais; desafios formais; contraintes.

\begin{abstract}
In France of the sixties, the group Ouvroir de Littérature Potentielle (Oulipo), presided by Raymond Queneau, proposed a new way to see Literature, deeply influenced by Mathematics. For the authors of this group, literary text, as a game, should be produced as a challenge, materialized under a formal restriction, so-called contrainte. Such restrictions, somehow similar to the traditional fixed forms of Western Literature, would potentialize classic rules into more radical restrictions, changing writing into a real table game, in which words, like pawns, would have very clear rules for moving, associating and positioning. The present paper aims to analyze this approach between Literature and formal challenges in the oulipian games, presenting, therefore, the main contraintes the group created and some of the texts that resulted from these playful restrictions.
\end{abstract}

Keywords: Oulipo; word games; formal challenges; contraintes. 
${ }^{1}$ A lista completa dos oulipianos, incluindo falecidos e vivos, inclui nomes como Noël Arnaud, Michèle Audin, Valérie Beaudouin, Marcel Bénabou, Jacques Bens, Claude Berge, André Blavier, Paul Braffort, Italo Calvino, François Caradec, Bernard Cerquiglini, Ross Chambers, Stanley Chapman, Marcel Duchamp, Jacques Duchateau, Luc Etienne, Frédéric Forte, Paul Fournel, Anne F. Garréta, Michelle Grangaud, Jacques Jouet, Latis, François Le Lionnais, Hervé Le Tellier, Jean Lescure, Daniel Levin Becker, Harry Mathews, Michèle Métail, Ian Monk, Oskar Pastior, Georges Perec, Raymond Queneau, Jean Queval, Pierre Rosenstiehl e Jacques Roubaud.
"Mais vale morrer conforme as regras do que escapar contra elas."

Jean Molière

\section{Introdução: O Oulipo e a écriture sous contrainte}

Na França da década de 60, onde os ambientes intelectuais apresentavam grande entusiasmo diante de uma proposta científica de descrição e análise da língua e da Literatura - o Estruturalismo -, ao mesmo tempo em que outros pensadores advogavam, como resposta à depressão pós-guerra e à crise do sentido, o Existencialismo e o Surrealismo, surgiu o grupo artístico Oulipo (Ouvroir de Littérature Potentielle), preconizando um novo olhar sobre a linguagem e o objeto literário.

Em um seminário em torno da obra de Raymond Queneau (Séminaire de Littérature Expérimentale - SLE), Noël Arnaud, Jacques Bens, Claude Berge, Jacques Duchateau, Jean Lescure, François Le Lionnais, Raymond Queneau e Albert-Marie Schmidt criaram o Oulipo, grupo que mais tarde veio a abranger grandes (e poucos) nomes da literatura francesa e mundial (FUX, 2010), como Georges Perec, Jacques Roubaud, Italo Calvino, Marcel Bénabou e outros ${ }^{1}$.

Em oposição às propostas surrealistas de uma escrita automática e inconsciente, Queneau, ex-integrante do movimento liderado por André Breton, do qual se afastou após diferenças ideológicas, teóricas e pessoais, pretendia com o Oulipo promover uma literatura da imanência, do jogo com os significantes, da potencialização estética (como o próprio nome do grupo revela) das arbitrariedades da língua e da literatura. Para tanto, negava-se o primado romanesco da inspiração e da noção de autor demiurgo romântico, buscando-se uma objetividade do texto literário, que requeria uma exploração de sua dimensão material, seja no nível fônico, léxico, sintático ou mesmo visual. Tal exploração estaria intimamente relacionada ao uso de formas fixas e restrições estruturais previamente acordadas, à guisa de jogos matemáticos e restrições algébricas e geométricas.

No entanto, não se pode confundir o Oulipo com um movimento literário, pois seus idealizadores, opondo-se com veemência à teoria das vanguardas, não tinham intenções políticas ou pretensões transformadoras da arte e da sociedade. Em vez disso, propunham-se apenas fruir e produzir literatura, gozando os prazeres do texto e da linguagem, e manipulando, como cientistas, a língua com extrema objetividade e argúcia. No documentário L'Oulipo - mode d'emploi (GUIDICELLI; FORTE, 
2010), os próprios integrantes do grupo se posicionam a respeito da experiência oulipiana, afirmando tratar-se de uma família, de um espaço de experimentação poético-matemática e mesmo do primeiro grupo literário de vocação universal.

No entanto, os próprios oulipianos afirmavam que o cerne de suas discussões não seria a produção de "Grande Literatura" - os chefs d'oeuvres, em oposição aos pieds d'oeuvres (OULIPO, 1973). Em vez disso, a ideia oulipiana era a de uma escrita lúdica, em vez do misticismo surrealista em torno da figura autoral. Todos poderiam escrever - até porque a escrita seria um produto da linguagem, e não do sujeito -, sendo as contraintes desenvolvidas pelo grupo semelhantes às regras de um jogo, de base axiomático-matemática, para libertar a escrita. Nas palavras dos próprios autores oulipianos:

OULIPO? O que é isso? O que é aquilo? O que é OU? $\mathrm{O}$ que é LI? O que é PO?

OU é OFICINA (OUVROIR), um ateliê. Para fabricar o quê? A LI.

LI é a literatura, o que se lê e o que se rasura. Que tipo de LI? A LIPO.

PO significa potencial. Literatura em quantidade ilimitada, potencialmente produtível até o fim dos tempos, em quantidades enormes, infinitas para todos os fins práticos.

QUEM? Em outras palavras, quem é responsável por essa empreitada insensata? Raymond Queneau, chamado RQ, um dos pais fundadores, e François Le Lionnais, chamado FLL, outro pai e compadre fundador, e primeiro presidente do grupo, seu Fraisident-Pondateur ${ }^{2}$.

O que fazem os OULIPIANOS, os membros do OULIPO (Calvino, Perec, Marcel Duchamp e outros, matemáticos e escritores, escritores-matemáticos e matemáticos-escritores)? Eles trabalham.

Certo, mas em QUÊ? Em fazer avançar a LIPO.

Certo, mas COMO?

Inventando contraintes. Contraintes novas e antigas, difíceis e menos difíceis e muito diiffí́cceis. A Literatura Oulipiana é uma LITERATURA SOB CONTRAINTES. (OULIPO, 2002, p.5)

Disfarçada de charada, ou "o que é, o que é?", enigma ou equação verbal bem ao gosto oulipiano, essa apresentação do Oulipo figura no prefácio de quase todas as obras coletivas do grupo, especialmente as coletâneas dos melhores textos, produzidos ludicamente em seus encontros mensais, em petits comités. Entre a leitura e a rasura, esses jogos literários, atrelados à pesquisa científica de estruturas formais da língua e dos textos, estão também profundamente vinculados a uma outra ciência: a Matemática, que constitui uma obsessão oulipiana, como tentativa de matematizar a linguagem e a literatura.

Trabalhando em oficina, como verdadeiros carpinteiros do verbo, os autores oulipianos entremeavam seu trabalho literário,
${ }^{2} \mathrm{Na}$ impossibilidade de traduzir a palavra, optou-se por manter a forma original. Trata-se de um trocadilho com o cargo de Président Fondateur de François Le Lionnais, jogando com os semas de frais (custos, em francês) e pont (jogadores contra a banca no cassino). 
${ }^{3}$ Conscientes de que o jogo com formas fixas arbitrárias não era propriamente uma inovação sua, os oulipianos passaram a homenagear, com o irônico nome de "plagiários por antecipação”, todos os autores que já trabalhavam com contraintes muito antes da criação do Oulipo, como inúmeros poetas latinos e barrocos. Os oulipianos consideravam ainda que havia em sua época (e haveria futuramente) outros autores oulipianos (considerados, pois, membros do grupo) inconscientes, os quais, mesmo sem saber da existência do Oulipo, realizavam literatura potencial. Nesse sentido, podemos citar Jorge Luís Borges e Osman Lins, cujas semelhanças com as obras oulipianas têm sido objeto de estudo de diversos trabalhos acadêmicos. a pesquisa científica e a paixão matemática, convergindo tais vetores para um mesmo ponto, central em sua poética: as contraintes, jogos ou restrições formais que ditam a ordem do dia em suas reuniões semanais e estruturam, como espinha dorsal algébrica, seus textos.

Termo de difícil tradução, mas que tem sentido próximo ao de "travas", "constrições" ou "restrições", as contraintes se dariam na forma geral de jogos verbais, desafios ou regras, como escrever um texto sem uma determinada letra, com um inovador padrão métrico, reiterando determinado trocadilho fonético etc., o que valoriza o caráter material da literatura e a imanência do texto como brincadeira de significantes, análoga à manipulação de variáveis em uma equação. Apaixonados pela forma e suas contingências, entrevendo padrões matemáticos em suas possibilidades e limitações, os autores oulipianos impunham-se regras constritivas no ato da escrita, tão arbitrárias quanto o próprio signo linguístico, o padrão de uma sequência numérica ou as normas de qualquer jogo, servindo-lhes de desafio e modelo estético ao mesmo tempo.

Se, por um lado, o uso de restrições formais em literatura não é algo criado pelos oulipianos ${ }^{3}$ (vide a tripartição da tragédia clássica; a morfologia do conto maravilhoso descrita por Propp (1984); as relações entre actantes narrativos de Greimas (1975); ou as formas fixas poéticas do soneto, do rondó, da balada etc.), por outro, é usufruto inegável para estes que levaram a ideia de restrição à máxima potência. Na verdade, enquanto na noção tradicional da restrição formal esta é apenas um pano de fundo, ou uma estrutura que funciona como suporte para o conteúdo do texto e seus significados, para o projeto oulipiano a contrainte é a matriz geradora do fenômeno textual, emergindo dela a obra de arte, e não de um suposto sujeito doador de sentidos (ALENCAR; MORAES, 2005).

No que tange a essa dicção sob restrições voluntárias, os oulipianos chegaram a definir a si mesmos, nos manifestos em torno da criação do grupo (redigidos como pastiches ao Manifesto Surrealista), em função das contraintes, como ponto de partida e de chegada de suas obras:

E um autor oulipiano, o que é ele? É um "rato que constrói para si mesmo um labirinto do qual se propõe a sair". Labirinto de quê? De palavras, de sons, de frases, de parágrafos, de capítulos, de livros, de bibliotecas, de prosa, de poesia, de tudo isso... (OULIPO, 2002, p.5).

Mais do que o oulipiano que define a contrainte, é a contrainte que define o oulipiano, como regra de ação, mode d'emploi ou mesmo interdição que cinde o sujeito, insere-o no regime simbólico da falta e da fala e fá-lo significar, ainda que sob arbitrárias restrições. 
Diferente de Dédalo, o arquiteto mitológico que abandona o labirinto sem enfrentá-lo, o autor oulipiano é enclausurador e enclausurado ao mesmo tempo, tendo de escrever segundo as contraintes que ele próprio se impõe. Tais restrições têm sempre caráter formal, sendo definidas como um axioma que o escritor deve seguir, a fim de redescobrir construções existentes na língua apenas como potência, veladas por trás da arbitrariedade do signo e reveladas por meio de um jogo com a própria arbitrariedade, em que se manipulam algebricamente as variáveis do idioma.

Sendo jogo, a contrainte é também desafio, como os problemas matemáticos que fascinavam os oulipianos, ou os trocadilhos e joguetes verbais que pontuam a história dos plagiários por "antecipação". Nesse sentido, como exemplo de jogo oulipiano materializado em uma contrainte de caráter literário-matemático, pode-se destacar o $S+7$, que embaralha mesmo as noções de letras e números.

Entre as diversas adaptações que essa contrainte recebeu nas reuniões do grupo francês, sua regra original implicava a retomada de um texto preexistente, sendo todos os seus substantivos (S) substituídos pelo sétimo substantivo $(\mathrm{S}+7)$ em um dicionário dado. Em curiosa relação, a letra $S$ e o número 7 que nomeiam o jogo ganham funções ambíguas entre a língua e a álgebra: como incógnita matemática, $\mathrm{S}$ determina um valor variável, em função do qual outra incógnita (o novo substantivo, ou $x$ ) será encontrada, por meio da adição com 7 . No entanto, nesse jogo de $\mathrm{x}=\mathrm{S}+7$, o algarismo 7 não pode ser considerado apenas um número, pois, na verdade, trata-se de 7 substantivos, ou 7S, que se adicionam ao substantivo inicial. Como letra usada em operação matemática, ou número que denota palavras, S e 7 formam algaravia de grafemas e algarismos, procedimento que forma novo poema a partir de uma permuta de seus termos, tomando por universo linguístico possível o dicionário.

Como a escolha da classe dos substantivos (S) e do número 7 é absolutamente arbitrária, uma vez que o jogo pode ocorrer com adjetivos, verbos ou advérbios e uma troca pela oitava, nona ou décima palavra (ou mesmo por termos anteriores no dicionário, à maneira de subtração), alguns oulipianos preferiam a forma geral $\mathrm{M} \pm \mathrm{n}$, que resguarda todas essas possibilidades sob o nome de uma equação literal (LESCURE, 1973).

Um dos mais célebres $\mathrm{M} \pm \mathrm{n}$, por seu caráter iconoclasta e a ironia com o próprio título do texto original, é construído por Georges Perec a partir de L'Étranger, de Baudelaire, o qual deu origem a L'Étreinte, jogando com substantivos e adjetivos segundo a fórmula $\mathrm{S} / \mathrm{A}+7$. 
${ }^{4}$ Ao longo deste artigo, optouse por não traduzir os textos oulipianos, visto que qualquer alteração na camada significante ocasionaria a perda da contrainte. Isso acontece especialmente com as contraintes relacionadas ao universo fonético, gráfico ou lexical.

\section{L'Étranger}

Qui aimes-tu le mieux, homme énigmatique, dis? Ton père, ta mère, ta soeur ou ton frère?

- Je n'ai ni père, ni mère, ni soeur, ni frère.

- Tes amis?

- Vous vous servez là d'une parole dont le sens m'est restée jusqu'à ce jour inconnu.

- Ta patrie?

- J'ignore sous quelle latitude elle est située.

- La beauté?

- Je l'aimerais volontiers, déesse et immortelle.

- L'or?

- Je le hais comme vous haïssez Dieu.

- Eh! qu'aimes-tu donc, extraordinaire étranger?

- J'aime les nuages... les nuages qui passent... là-bas... là-bas... les merveilleux nuages! (BAUDELAIRE, 2007, p.36)

\section{L'Étreinte}

- Qui aimes-tu le mieux, homochromie ennéagonale, dis? ta perfection, ton mérinos, ta soif ou ton frétillement?

- Je n'ai ni perfection, ni mérinos, ni soif, ni frétillement.

- Tes amidons?

- Vous vous servez là d'un paros dont la sensiblerie m'est restée jusqu'à ce jouteur inconnue.

- Ton patron?

- J'ignore sous quel laudanum il est situé.

- Le bécard?

- Je l'aimerais volontiers, défaut et immortel.

- L'orangeade?

- Je la hais, comme vous haïssez. Différenciation.

- Eb! qu'aimes-tu donc, extraordinaire étreinte?

- J'aime les nucléarisations... les nucléarisations qui passent... làbas... là-bas... les merveilleuses nucléarisations! (PEREC apud LESCURE, 1973) ${ }^{4}$

Se no poema de Baudelaire estava em jogo um estrangeiro, homem deslocado da família, da pátria e mesmo do sentido da beleza, são as palavras, em L'Étreinte, que se tornam estrangeiras, lançadas na propulsão de $\mathrm{S} / \mathrm{A}+7$ para um contexto em que se encaixam perfeitamente sob o viés da sintaxe, mas revelam uma desterritorialização semântica, um mal-estar do vocábulo que é l'étranger, ao mesmo tempo em que está étreint em um lugar que não reconhece como seu.

Étreintes e étrangères, presas no jogo em que devem, paradoxalmente, se mover segundo as regras do tabuleiro que lhes é estranho, as palavras, na literatura oulipiana, são sempre reféns de uma contrainte, que as faz circular segundo uma retórica própria. A dinâmica do jogo define, pois, posições, permutas e associações entre as palavras, como pontos negros contra a página branca, resultado de dados que Mallarmé (1951) confirma em sua poética, sob a máxima de que un coup de dés jamais n'abolira le hasard. 


\section{A contrainte como jogo retórico: interdição e liberdade}

Tais quais restrições de movimento da mão que escreve, ou da palavra que se articula, as contraintes são como as regras de qualquer jogo, atividade humana que não exige mais do que um participante e uma proibição: não pisar fora do meio-fio, não mover uma peça do jogo de damas para trás, não pegar o morto sem ao menos uma canastra suja. Criatura que joga, homo ludens (HUIZINGA, 2007), mais do que criatura que sabe, homo sapiens, o homem joga justamente porque não sabe: assim como se desconhece o destino da vida, ignora-se o desfecho da partida, da disputa, da escrita a partir de uma regra a priori. Escrevendo sob uma restrição, o autor não sabe o fim de seu texto, pois é a produção, antes do produto, que conta aqui, tal qual em qualquer atividade lúdica.

Mesmo em suas formas mais simples, ao nível animal, o jogo é mais do que um fenômeno fisiológico ou um reflexo psicológico. É uma função significante, isto é, encerra um determinado sentido. No jogo existe alguma coisa "em jogo" que transcende as necessidades imediatas da vida e confere um sentido à ação. Todo jogo significa alguma coisa. (HUIZINGA, 2007, p.4)

Jogando para significar a si mesmo e ao mundo, o participante ou competidor está sempre, a partir de uma regra arbitrária, construindo sentidos e experiências. Dos mais simples trava-línguas, a língua do pê em Português (Por-por-tu-pu-guês-pês) ou o verlan francês, às mais elaboradas contraintes oulipianas, como o livro de poemas $\epsilon$, que se estrutura como tabuleiro de gô (ROUBAUD, 1967), a língua está sempre fadada a uma norma de associação. Permeada mesmo na fala cotidiana por regras de combinatória (adjetivos junto a substantivos, advérbios junto a verbos etc.), é da natureza da própria linguagem, ainda que mais especialmente na literatura, a necessidade de posicionar as peças sob determinados padrões no tabuleiro.

À semelhança do xadrez, ou qualquer jogo, desde os brinquedos infantis até os espetáculos de palco, o texto literário constitui um jogo: possui regras próprias, variáveis de acordo com a noção de gênero, espécie e formas, que se impõem ao jogador, à pessoa que pretenda realizar os movimentos pressupostos pelo jogo. Tanto num como noutro tipo de jogo, a desobediência às normas significa inabilidade ou recusa de jogar; para aderir ao jogo, o jogador deve, antecipadamente, conhecer as regras que o governam, sob pena de não participar dos movimentos; qualquer transgressão, a que título for, violenta o jogo como tal. [...] Aqui se põe uma diferença que cumpre esclarecer para o bom entendi- 
${ }^{5}$ Quod erat demonstrandum, ou "Conforme se queria demonstrar", em Português. mento da questão: enquanto as regras do jogo não literário são fixas e universais, as do jogo literário submetem-se à discussão, tal a mobilidade interna conferida pelo instrumento linguístico, a metáfora. (MOISÉS, 1982, p.53)

Como jogo, a escrita oulipiana é sempre a escrita de um prazer, o que não diminui, no entanto, seu valor. O prazer da criança que brinca segundo as regras, dos corpos que se amam conforme uma gramática de posições, da boca que ri em um trava-língua chistoso: todo prazer é oriundo de um ritmo, repetição ou padrão regrado, tempo do corpo e da linguagem, que a contrainte faz aparecer. Segundo François Le Lionnais (1973), "na medida em que são a realidade dos poetas, divertimentos, chistes e trapaças pertencem ainda à poesia. A literatura potencial é, portanto, a coisa mais séria do mundo. Q.E.D" ${ }^{5 ”}$.

No que diz respeito a esse prazer dos jogos verbais oulipianos, entre a liberdade de escolha de uma peça e a constrição na forma de movê-la sobre o tabuleiro, as contraintes ganham uma dimensão não só estética, mas política. No movimento dialético entre liberar e prender, falar e calar - alternância erótica do verbo em contrainte -, o prazer aqui está ligado à tarefa paradoxal lançada por Roland Barthes (1994): libertar a literatura por meio da própria língua, reproduzindo as arbitrariedades combinatórias do sistema e do signo linguístico através das também arbitrárias contraintes a serem respeitadas no ato da escrita.

A esse respeito, é célebre a visão barthesiana de que a literatura é um logro que foge ao fascismo da língua, visto que esta obriga o sujeito a se expressar de acordo com determinadas regras de associação e construção. Para o pensador francês, "é no interior da língua que a língua deve ser combatida, desviada: não pela mensagem de que ela é instrumento, mas pelo jogo de palavras de que ela é o teatro" (BARTHES, 1994, p.17). Tal afirmação enseja um paradoxo em que reside sua força crítica: a liberdade artística deve quebrar a regra por meio da própria regra, afinal "é no interior da língua que a língua deve ser combatida".

A literatura não é feita, pois, fora das articulações lógicas e restritivas da linguagem, mas sim jogando com essas regras e aplicando-as de forma inusitada. O logro não rompe com o jogo; o logro é uma substituição da regra tradicional por outra implícita. Mesmo a trapaça, seja com cartas em um baralho ou palavras em um texto, instaura uma nova regra (HUIZINGA, 2007). A contrainte, no jogo literário, é então uma tentativa de trapacear, trocando as regras da partida. No entanto, a suspensão de uma restrição incorre sempre em outra, sendo inescapável o estar preso, mas facultativa a escolha da prisão a que se vai submeter à escrita. 
Tal prisão consentida, contudo, pode ser extremamente dura, como o jogo verbal de Là rien que là toute là, criado por François Le Lionnais dentro de um grupo especial, as propositions à la limite. Nessa categoria, o primeiro presidente do Oulipo incluiu contraintes que explorassem os limites mais extremos da literatura, como jogo cujas regras pudessem ser de fato seguidas apenas por veteranos. Entre elas, là rien que là toute là é uma forma de trapaça às regras da língua que desencoraja jogadores iniciantes, uma vez que subverte as associações sintagmáticas padrão e prescreve uma poética barrada de termos lexicais, aberta apenas aos functivos gramaticais. Isso implica que um texto escrito segundo essa contrainte não pode conter substantivos, adjetivos ou verbos, estruturando-se apenas de conectivos, advérbios e pronomes, como se observa a seguir.

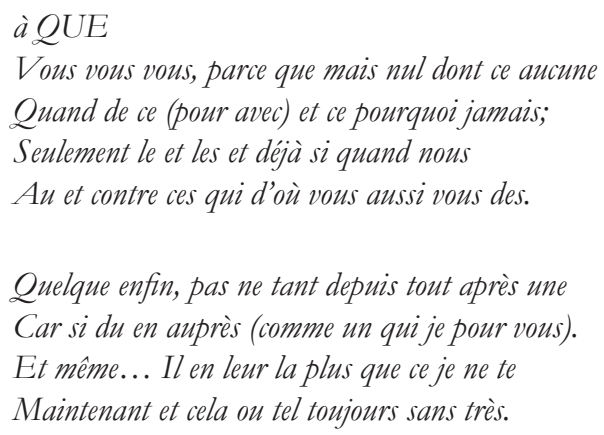

Désormais tu son donc! et tu bien les ici

Mais grâce à lorsque sur dont un les des en eux

Tu Tu Tu à travers les nul dont ce aucune. (LE LIONNAIS apud OULIPO, 2011)

Livre para escolher a palavra que quiser dentro dos restritos arcabouços vocabulares disponíveis, o eu-lírico de à Que tem poucas peças para jogar, mas pode movê-las como bem entender, gerando combinações improváveis. Se, na linguagem cotidiana, conectivos, pronomes e advérbios servem para relacionar ou apontar para os termos léxicos, apenas estruturando a cadeia sintática preenchida por eles, à Que é uma estrutura vazia: a forma fixa do soneto ganha aqui ares de esqueleto descarnado, cuja musculatura vocabular fosse subtraída. Resta-lhe, então, apenas um truncamento da palavra que nada diz, gagueira de formas átonas impronunciáveis em cadeia, como "ce je ne te", este eu não tu que escapa à língua.

Se uma das características do jogo, para Huizinga (2007), é justamente a suspensão da instrumentalidade da ação, substituída pelo puro gozo da encenação - na batalha enxadrística, na 
vida das bonecas ou na fabulação do faz-de-conta -, a contrainte là rien que là toute là cria também encenação de discurso. A materialidade do verbo - moterialisme de Lacan (1976) - é o que sobra de um poema de estruturas ocas, que só faz semblant de discurso, mas não tem nada a dizer, por não ter com que dizer.

Interlocução impossível, a busca malograda de um Outro, à Que o poema pudesse falar, pode ser entrevista na reiteração das coordenadas pronominais "vous vous vous" e "tu tu tu" que abrem e fecham o texto. É "à travers les nul dont ce aucune”, através do nada cujo nenhum, que as palavras, desprovidas de sentido, viram peças de jogo, tentando convidar um adversário ou parceiro para a partida, a quem porém, o discurso nada diz. Livre do significado - ausente -, mas preso pela contrainte - pungente -, há um nada no texto que se diz sob interdição.

De maneira análoga, para a psicanálise tal interdição tem papel fundamental na constituição do sujeito e sua inserção no regime simbólico, enquanto jogo de posições com os outros significantes em torno do tabuleiro ou da mesa para o carteado. Para Lacan (1992), é mesmo em volta do morto no bridge que os significantes giram, partida em função de um centro vazio, que ordena, como contrainte, a circulação de todas as cartas ou palavras.

Morto calado e desconhecido que põe os outros a jogar, seu silêncio é intimidador, instalando-se como regra fundante da mesa ou Lei que insere o sujeito na linguagem (LACAN, 1988), defrontado com a impossibilidade e a interdição do gozo proibido, ou o acesso às cartas que não lhe cabem, intocáveis no centro da mesa. Falo castrado, ou fala castrada, a contrainte é uma mímica dessa interdição ao corpo barrado, em que a palavra é fantasmagoria do desejo que não se completa. Imitando a proibição simbólica do Pai, a proibição sígnica do Oulipo faz do texto o objeto de um desejo, que se configura nos interstícios da legislação do Outro e das contraintes literárias.

Entre castração e liberdade, interdição e gozo, o autor que escreve segundo restrições formais conscientemente impostas cria um duplo da castração, que permite, talvez, um afrouxamento de outras constrições. Afinal, se é ao consciente que cabe banir e represar os afetos a que se ligam as representações inconscientes, um sujeito que dedica toda a sua atenção a conter uma letra, repetir um padrão métrico ou usar determinada estrutura sintática troca a censura do superego por outra consciente, libertando-se inclusive da opressora folha em branco.

Em vez, então, da interdição primeira - incesto proibido, mãe inatingível, cordão umbilical não suturável -, um grupo que se reúne para criar interdições de escrita e significação gera uma virtual infinidade de repressões e estruturas, que deslocam 
a castração do centro do jogo e põem-na em circulação, como só mais uma contrainte da partida. "Tudo se passa como se, em verdade, o texto literário constituísse $n$ jogos, ou um jogo múltiplo, com vários sistemas de leis, conjugados num hipersistema, que as aglutina e as ordena" (MOISÉS, 1982, p.116).

Uma das formas desse lúdico transgressor, em que a contrainte é lei que subverte uma lei anterior (a de respeito ao cânone), ficou conhecida como La rédondance chez Phane Armé, jogo que desconstrói textos clássicos da tradição ocidental. Baseada inicialmente nos sonetos de Mallarmé (mas aplicável a qualquer outro soneto), essa restrição consiste na redação de um breve poema, formado apenas pelo final de cada verso de um soneto matriz. A ideia geral é que, mesmo preservando apenas uma parte do texto original, o efeito estético permaneceria, talvez de forma ainda mais intensa, pois todo o restante de cada verso seria apenas redundante, como sugere o nome da contrainte.

Aliás, se ao preservarmos apenas a parte final do nome Stéphane Mallarmé, como no procedimento constritivo, encontramos Phane Armé, segunda parte do nome do jogo, que indica ainda os semas de - phane (sufixo francês oriundo do grego, indicando a noção de "parecer") e armé (armado). Poema aparentemente armado com uma falta, corte do início de cada verso, trata-se aqui de um significante sem origem, precedido de um buraco na página e no verso, como promessa de jogo.

Em um texto explicativo sobre essa contrainte, Queneau apresenta como exemplo uma versão "hai-kaizante" (QUENEAU, 1973, p.181) do célebre soneto de Mallarmé em -yx, que se transcreve a seguir para fins de cotejo com o poema produzido por Queneau.

Ses purs ongles très haut dédiant leur onyx L'Angoisse, ce minuit, soutient, lampadophore, Maint rêve vespéral brûlé par le Phénix Que ne recueille pas de cinéraire amphore

Sur les crédences, au salon vide: nul ptyx, Aboli bibelot d'inanité sonore, (Car le Maître est allé puiser des pleurs au Styx Avec ce seul objet dont le Néant s'bonore).

Mais proche la croisée au nord vacante, un or Agonise selon peut-être le décor

Des licornes ruant du feu contre une nixe,

Elle, défunte nue en le miroir, encor

Que, dans l'oubli fermé par le cadre, se fixe

De scintillations sitôt le septuor. (MALLARMÉ, 1951, p.68-69) 
Conotando uma atmosfera imprecisa e religiosa, com imagens místicas e evanescentes, típicas da estética simbolista, tem-se aqui uma forma fixa nada etérea ou fluida: o soneto, contrainte clássica da literatura ocidental, revela todo o seu poder nesse texto. Além da rigidez de metrificação e estrofação, as rimas, elemento chave em qualquer soneto regular, aqui ganham nova dimensão, uma vez que Mallarmé se põe a combinar sons raros em francês, como a difícil rima em $-y x$.

Como as incógnitas y e x de qualquer equação, tal rima sugere a indefinição de sentidos do próprio texto, cujas imagens poéticas aproximam-se do inefável. Se, por outro lado, as demais rimas são em -or, sugerindo o ouro, o brilho e o Absoluto, as rimas em $-y x$ apontam para uma labilidade, enquanto equação cujo resultado será sempre uma relação entre termos que se definem mutuamente, em circuito fechado, mas não adquirem um valor definido.

Inspirada pela Angústia, enquanto carência, e não pela Musa como presença, a vacância se materializa em nul ptyx, nenhum espécime de algo que não existe em língua alguma: ptyx é palavra sem significado e com infinitos significados, cuja vacuidade reflete-se no ambiente descrito pelo poema. Ânfora sem cinzas, búzio de oca sonoridade, espelho cujo reflexo se esvai: é como enigma da Sphinx, entrevista em todo o poema, que o texto se constrói.

Por meio da contrainte de La rédondance chez Phane Armé, tais semas são potencializados no poema de Mallarmé, sob a reescritura apócrifa de Queneau (1973):

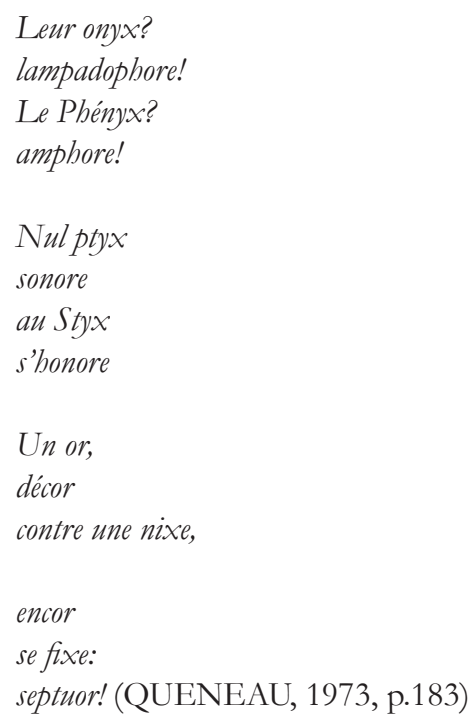

Se o poema original apontava para uma impossibilidade da própria linguagem e um curto circuito na determinação de seus 
termos, de modo que x só se entende a partir de y e y só existe em função de $\mathrm{x}$ na própria rima que estrutura o soneto, essa intransitividade do texto se torna na versão de Queneau ainda mais evidente. A rédondance, afinal, não marca só o que foi suprimido dos versos, mas a relação redundante entre x e y em y = $\mathrm{a}+\mathrm{bx}$, ou entre as palavras que formam o poema, cuja significação emerge apenas de sua relação enquanto vazio de sentido. O poema "hai-kaizante" de Queneau, em uma intercalação de perguntas e respostas exclamativas desencontradas, defronta-se, então, com uma aporia da linguagem, entre as incógnitas de $-y x$ ou uma homófona rima em hors, em busca de um sentido nas relações algébricas do texto ou em seu fora, que jamais se apreende, porém.

De maneira análoga, outros jogos oulipianos se erigem a partir de um corte, ou falta, na medida em que a própria noção de casa vazia (DELEUZE, 1979) é inerente ao Estruturalismo e à concepção oulipiana da linguagem, bem como ao funcionamento de uma série de jogos de tabuleiro. Afinal, é só a partir de um espaçamento que as peças podem se mover, assim como as palavras que fazem a estrutura girar, em sua dinâmica própria.

O desafio da bola de neve (boule de neige, no original) permite uma ressignificação dessa ausência a partir da qual todo signo fala, apontando não para um significado estável, mas para uma significação cifrada como outro significante. Tal contrainte consiste na elaboração de um poema cujo primeiro verso contenha apenas uma letra; o segundo verso, duas letras; o terceiro, três letras, e assim sucessivamente, como uma bola de neve que aumenta progressivamente ao rolar montanha a baixo. Trata-se, em termos matemáticos, de um jogo de sequência numérica, baseado em uma progressão aritmética de razão $r=1$.

Em lugar de simplesmente nomear um referente, servindo de espelho ou cópia do real, os vocábulos da bola de neve apontam entre si mutuamente, sendo a falta de uma letra o que automaticamente remete à próxima palavra, que a excede no que tange ao grafema faltante. No entanto, a adição de uma letra nunca é o suficiente, pois permanece sempre uma lacuna, prefixo ou sufixo que sempre pode ser acrescido, aumentando o vocábulo e fazendo crescer a esfera nevada.

Seguindo essa contrainte, Jean Lescure (1973) construiu um poema concreto, em que a bola de neve primeiro decresce para depois aumentar, retornando, invariavelmente, ao ponto inicial da queda. 


impitoyablement
obsessionnelle
pourchasseuse
déclamatoire
prédestinée
auparavant
innocente
pourtant
gaîment
câline
refit
elle
par
un
$x$
de
feu
cent
mille
douces
marques
aimables
blessures
véritables
bémorragies
inépuisables
interventions
contraignantes
impitoyablement
SCURE, 1973, p.105)

Se essa é uma bola de neve que contraria o percurso do fenômeno natural, em que a massa de gelo apenas aumenta ao longo da queda, é porque reproduz, na macroestrutura poemática, por meio da métrica atrelada ao número de letras, o formato do X que funciona como centro gerador do texto e ponto de inflexão, no verso central. Do mesmo modo, o x da equação, enquanto incognoscível, é um significante sem significado - ou de infinitos significados, mas sempre ausentes, afastando-se infinitamente do centro à medida que rola a bola de neve. Ademais, o x do tabuleiro, ponto de chegada dos peões, é também apenas um lábil fim, uma vez que as partidas reiniciam sempre e a temporária chegada transforma-se em ponto de partida.

Uma possível leitura, pois, pode aproximar "ela" (12 verso), "impiedosamente obsessiva perseguidora declamatória predestinada", da própria língua enquanto força motriz da literatura, que nasce a partir de uma casa vazia $\mathrm{X}$, a qual se tenta malfadadamente preencher segundo a contrainte: os signos, como as palavras da bola de neve, sucedem-se ininterruptamente, tentando preencher a vacância do significante anterior, mas sempre engendrando novo hiato. Esse " $x$ de feu", ardente e consumindo a si mesmo, como a chama que devora o comburente e o com- 
bustível, fazendo mesmo derreter uma bola de neve, deixa em seu caminho "cent mille" marcas, feridas, traços, enfim, como os que se cicatrizam a posteriori como números ou letras, mas jamais perdem seu caráter de escrita nem a dimensão de "interventions contraignantes" - contraintes, pois - a partir das quais funcionam os jogos oulipianos.

Ainda no que tange à relação entre Matemática e Literatura na formação das contraintes, opera-se aqui, como nos demais textos do Oulipo, uma releitura da tradicional relação entre significante e significado no que diz respeito à significação, pois é da restrição formal que surge o sentido, na forma de significantes sempre adiados. Afinal, se "antes inocente, porém alegremente carinhosa" ("auparavant innocente pourtant gaîment câline"), o que sugere uma pretensa docilidade da língua às concepções tradicionais de sujeito autoral e significado a priori, a literatura é "refeita por um x" ("refit elle par un $x$ "), significante puro que inverte não só os sentidos, mas a estrutura poemática, como "hemorragia inestancável" ("bémorragies inépuisables") a partir de uma fenda material na superfície da página.

Como corte, lacuna, desafio ou obstáculo, a bola de neve, tal qual todas as outras contraintes ${ }^{6}$, remete-nos a uma incompletude ou um percurso: os jogos literários oulipianos, como quaisquer outros na história da humanidade, pressupõem um dinamismo, um sempre já atualizado a cada lance de dados, que cabe ao jogador por em cena. Em lugar de textos vistos como objetos completos, sacralizados no cânone, a proposta do Oulipo faz da literatura um moto-contínuo, com textos nunca acabados, uma vez que todo desafio pode ser levado mais à frente, como partidas sem fim que não redundam em vitória, derrota ou mesmo empate.

\section{Considerações finais}

Jogo individual, como o da escrita, o da leitura, ou da paciência, a literatura oulipiana também é ludo em que podem jogar mais: até um grupo de sujeitos dispostos a se lançarem juntos no labirinto, como aqueles que integram uma equipe, uma oficina, um ouvroir. Basta-lhes, apenas, disposição para inventar e seguir regras, como fazemos a cada vez que falamos, escrevemos, amamos ou elaboramos afetos em nosso inconsciente. Ações sempre regradas e ritmadas, emitir sons, garatujar letras, enredar corpos ou sonhar gozos, estão intimamente relacionados ao que se repete, que tem ritmo, que segue padrões associativos, permutativos ou restritivos.
${ }^{6}$ A lista completa das contraintes criadas pelos primeiros oulipianos e seus sucessores pode ser encontrada no site do grupo, sendo atualizada até hoje todas as quintas-feiras (OULIPO, 2012). 
Se uma das maiores fontes de prazer do homem é entrever e sentir, na alma e na carne, padrões, regras, lógica, a escrita oulipiana é uma prática constante de fazer da regra, enquanto contrainte, um acontecimento. Fonte de aflição e prazer, constrição e mobilidade de quem escreve, lê ou resolve uma equação matemática.

De textos algébricos, calcados em um axiomatismo da linguagem e do pensamento, a literatura oulipiana marcou, na metade do século XX, uma ruptura com as tendências de sua época e uma revitalização da ideia da escrita como puro jogo, prazer, encenação, fabulação e atividade lúdica, que faz rir ou gozar como semblant da única coisa que realmente há: estar presente na cena. Escrita enquanto ato, processo mais do que produto - de percorrer o tabuleiro da contrainte -, é só como linguagem que existem o sentido e o texto no Oulipo. Produzido pelo verbo, e não pelo sujeito, o texto oulipiano lembra-nos que apenas na linguagem o homem se faz presente, se inscreve no mundo e comparece na cena, diante das peças, cartas, fichas ou dados.

Sem anterioridade ou posteridade, metafísica da presença ou teleologia da escrita, em um texto como obra da contrainte, é a própria linguagem que faz falar e cria, não só o universo da obra, mas o sujeito empírico que a lê ou escreve. Experiência máxima da dessubjetivação, trata-se sempre aqui de um texto que se diz, em vez de querer dizer algo a alguém. Como acontecimento, e não como mensagem, o poema oulipiano é jogo, desprovido de caráter instrumental, pelo puro prazer da regra ou da contrainte, que forma o texto como um lance de dados, conforme bem o dissera Mallarmé.

\section{Referências}

aLENCAR, Ana Maria de; MORAES, Ana Lúcia. O Oulipo e as oficinas de escrita. Revista Terceira Margem. Revista do Programa de Pós-Graduação em Ciência da Literatura. Rio de Janeiro: Universidade Federal do Rio de Janeiro, Ano IX, n. 13, 2005.

BARTHES, Roland. Aula. São Paulo: Cultrix, 1994.

BAUDELAIRE, Charles. Pequenos poemas em prosa - O spleen de Paris. São Paulo: Hedra, 2007.

DELEUZE, Gilles. À quoi reconnait-on le structuralisme? In: CHÂTELET, François. La philosophie au XX siècle. Paris: Marabout, 1979. 
FUX, Jacques. A matemática em Georges Perec e Jorge Luis Borges: um estudo comparativo. Tese de doutorado. Universidade Federal de Minas Gerais, Faculdade de Letras. 2010. 249 f.

GREIMAS, Algirdas Julius. Ensaios de Semiótica Poética. São Paulo: Cultrix, 1975.

GUIDICELLI, Jean-Claude; FORTE, Frédéric. L'Oulipomode d'emploi. Paris: DOCSIDE, 2010. 1DVD.

HUIZINGA, Johan. Homo ludens. São Paulo: Perspectiva, 2007.

LACAN, Jacques. A Ética da Psicanálise. Seminário VII. Rio de Janeiro: Jorge Zahar, 1988.

Communication et discussions au symposium international du

John Hopkins Center à Baltimore. Paris: Chollet, 1966.

LE LIONNAIS, François. La lipo: Le premier manifeste. In: OULIPO. La littérature potentielle. Paris: Gallimard, 1973.

LESCURE, Jean. La méthode $\mathrm{S}+7$ (cas particulier de la méthode $\mathrm{M} \pm \mathrm{n})$. In: OULIPO. La littérature potentielle. Paris: Gallimard, 1973.

MALLARMÉ, Stéphane. Oewvres complètes. Paris: Gallimard, 1951.

MOISÉS, Massaud. Literatura: mundo e forma. São Paulo: Cultrix, 1982.

OULIPO. Abrégé de littérature potentielle. Paris: Mille et une nuits, 2002.

Le Collège de 'Pataphysique et l'Oulipo. In: OULIPO.

La littérature potentielle. Paris: Gallimard, 1973.

OULIPO. Owvroir de Littérature Potentielle. Disponível

em $<$ http://www.oulipo.net/>.

PROPP, Vladimir Iakovlevich. Morfologia do conto maravilhoso.

Rio de Janeiro: Forense-Universitária, 1984.

QUENEAU, Raymond. La redondance chez Phane Armé. In: OULIPO. La littérature potentielle. Paris: Gallimard, 1973.

ROUBAUD, Jacques. E. Paris: Gallimard, 1967. 